\title{
Ações do corpo humano, mente/cérebro e linguagem
}

José Roque Aguirra Roncari

Doutor em Letras pela Unesp e Professor da UEM

\section{Resumo}

Descobrimos que, se a linguagem e o corpo bumano são uma realidade só, se a linguagem é física/matéria tanto quanto um órgãa mental (mente/cérebro) do corpo, conforme Chomsky (1997) cuja gênese biológica nos acontece e se desenvolve a partir de nosso interior corpóreo mental. Se a linguagem também executa ações, conforme Ludwig Wittgenstein (o primeiro e o segundo), então, isto pode significar que educar o corpo humano, implica educar também a linguagem ordinária que o corpo usa para viver em ambientes sociais. Ambos, sempre agem em conjunto e aprendem a conhecer o mundo através da práxis física e social. Se educar a linguagem passa por educar o corpo, então, resulta que ambas as ações podem correlacionarem-se a epistemologias como a da Educaşão Física, Filosofia da Educação ou à da ciência de parte da naturez̧a humana: a Faculdade de Linguagem universal, que permite ao Homem pensar, fazer e ser humano mediante a aquisição de qualquer língua natural.

Palavras-chave: Atos; Contra-Sensos; Ambigüidades.

\begin{abstract}
If human language and human body are physical matter such and as such the former is a mental organ (mind/brain) of body, according to Chomsky (1997) which biological growth happens to us and develops from inside our mental body. If language does actions with speech, as says Luduwig Wittgenstein (the first and the second one), so, that can means: to educate human body, implies to educate ordinary language used by the body as well to live in social environment. Both language and body together always acts and learns to know the world through physical and social praxis. If to educate language goes through to educate the body, so, they may have on a par epistemology of human nature.
\end{abstract}

Keywords: Speech Acts; Non-Senses; Ambiguities. 


\section{Introdução}

I

nvestigamos no projeto que apresentamos abaixo os processos de explicitação de traços internos subjacentes, normalmente traços externos significativos correspondentes que lhes são contíguos, expressos também através de proposições tácitas, tais como: nos gestos ambíguos, olhares sutis, etc., enfim, movimentos do corpo, dos sistemas de pensamento e linguagem humanos que se manifestam mediante velocidade tão rápida e instantânea quanto o uso que rotineiramente fazemos do conhecimento lingüístico e extra-lingüístico. Assim, acreditamos que seja possível revelar fenômenos sociais e lingüísticos surpreendentes relativos tanto à estrutura lingüística quanto ao uso ordinário que rotineiramente fazemos da linguagem em diversas esferas do pensamento e ações humanas: ações escolares, artísticas, civis, trabalhistas, humorísticas, éticas, morais, políticas, científicas, jurídicas, culturais, místicas, etc. Em resumo, ações que ajudam a desenhar um pequeno painel, porém, muito vivo - um tableaux vivant - conforme expressão original de Ludwig Wittgenstein (o primeiro e o segundo), ou Faculdade de Linguagem, em versão do The Minimalist Program, por designação científica exposta recentemente em Chomsky (1997) - do mundo das experiências humanas. Para tanto, metodologicamente, estudamos alguns argumentos de base destas teses.

\section{Desenvolvimento}

(A) Epistemologia de raízes minimalistas: quanto mais investigamos, estudamos e observamos, verificamos que a linguagem se presta à expressão de um emaranhado de atividades com os mais variados significados e propósitos além da "comunicação". Chomsky (1980), por exemplo, já constatava:

What is the function of language? It is frequently alleged that the function of language is communication, that its 'essential purpose' is to enable people to communicate with one another. It is further alleged that only by attending to this essential purpose can we make any sense of nature of language. 
It is not easy to evaluate this contention. What does it mean to say that language has an 'essential purpose'? Suppose that in the quiet of my study I think about a problem, using language, and even write down what I think. Suppose that someone speaks honestly, merely out of a sense of integrity, fully aware that his audience will refuse to comprehend or even consider what he is saying. Consider informal conversation conducted for the sole purpose of maintaining casual friendly relations, with no particular concern as to its content. Are these examples of 'communications'? If so, what do we mean by 'communication' in the absence of an audience, or with no intention to convey information or modify belief or attitude?

It seems that either we must deprive the notion 'communication' of all significance, or else we must reject the view that the purpose of language is communication. While it is quite commonly argued that the purpose of language is communication and that it is pointless to study language apart from its communicative function, there is no formulation of this belief, to my knowledge, from which any substantive proposals follow. The same may be said of the idea that the essential purpose of language is to achieve certain instrumental ends, to satisfy needs, and so on. Surely language can be used for such purposes - or for others. It is difficult to say what 'the purpose' of language is, except, perhaps, the expression of thought, a rather empty formulation. The functions of language are various. It is unclear what might be meant by the statement that some of them are 'central' or 'essential'.

A more productive suggestion is that functional considerations determine the character of linguistic rules. Suppose it can be shown, for example, the some rule of English grammar facilitates a perceptual strategy of sentence analysis. Then we have the basis for a functional explanation for the linguistic rule. But several questions arise, apart from the matter of the source of the perceptual strategy. Is the linguistic rule a true universal? If so, then the functional analysis is relevant only on the evolutionary level; human languages must have this rule or one like it, by virtue of a species property. Suppose, on the contrary, that the linguistic rule is learned. We may still maintain the functional explanation, but it will now to do with the evolution of English. That is, English developed in such a way as to accord with this principle. In either case, the functional explanation applies on the evolutionary level - either the evolution of the organism or of the language. The child does not acquire the rule by virtue of its function any more than he learns to have an eye because of the advantage of sight. (Itálico do autor) (Chomsky, 1980, p. 229-31)

Apenas ressaltando o último período: "The child does not acquire the rule [linguagem] by virtue of its function any more than he learns to have an eye because of the advantage of sight [visão mental]."; aqui também, talvez, a atividade acabe se passando como na descrição feita por Ralph Cudworth citada mais adiante, na Conclusão.

O olho da criança, por exemplo, mais tarde, o mesmo olho [também mental], agora, de um ser humano maduro, vivido e experiente, com os sistemas de pensamento que já sabem transformar operações passivas das 
percepções visuais e auditivas em operações reflexivas, enquanto interagem com a faculdade de linguagem como a de um desenhista ou músico engenhoso. Daí que, observará, então, com prazer, as elegâncias e curiosidades artísticas dos traços e sombras de uma gravura com os olhos de um grande pintor, ou o deleite com um ouvido de grande músico, interpretando a arte das minuciosidades de vozes melódicas semelhantemente ao que executam os ouvidos de outros músicos. Tais aspectos não são novidade nem mesmo a Wittgenstein (1974:190) que também assim o reconhece e corrobora com as posições de Chomsky (1980) e (2005).

Então, em meio ao emaranhado de ações que a linguagem e o corpo humano expressam, consideramos uma em específico como exemplo; aquela a que Hirigoyan (2005) se refere e perguntamos qual a racionalidade ou irracionalidade desta ação.

(B) Epistemologia de raízes pragmáticas: ela emerge de uma circunstância problemática muito particular, isto é, quando o uso da linguagem comum nos ofusca a visão de certas evidências importantes e significativas. A referida psicanalista aponta o dedo em direção a uma realidade bastante delicada e assim a caracteriza:

'[A ação X] é toda ação, gesto ou palavra que atinja, pela repetição, a autoestima e a segurança de um indivíduo, fazendo-o duvidar de si e de sua competência', explicou a autora em entrevista a ISTO É. 'Em geral são ações ambíguas, pouco claras, de tal forma que a vítima não possa afirmar que houve má intenção', diz. O objetivo do agressor pode ser livrar-se de alguém ou esmagar o amor próprio do outro para satisfazer a uma necessidade perversa.' E mais: 'Em geral, as pessoas são perseguidas por ter qualidades a mais e não a menos. Os indivíduos apagados não amedrontam ninguém. São as competências que despertam a inveja e a insegurança.'

Marie-France notou que muitos dos pacientes que se queixavam de perseguição no trabalho eram indivíduos saudáveis em outras situações sociais.

O trabalho da psicanalista ficou bastante conhecido por tratar deste assunto relacionado à linguagem, tanto que seu livro rendeu uma série de interessantes matérias jornalísticas em vários países europeus; fato que também chamou a atenção aqui no Brasil e foi objeto de inteligente matéria crítica escrita por Ferraz \& Góes (1999, p. 4). 
A pergunta que fazemos é a seguinte: $\mathrm{O}$ que, às vezes, como neste caso muito particular, fenômenos internos à linguagem ordinária tornam tortuoso e obscuro este tipo de uso da linguagem comum, que - em sua forma interna - expressa significados perversos com roupagens de aparência tão inofensiva em sua forma pública externa?

O problema fundamental, neste caso, sempre foi, então, descobrir com segurança e explicitar inequivocamente ao mundo o que querem especificamente dizer os gestos, as palavras ou as ações executadas por alguém em uma circunstância particular. Como resolver e comprovar que tais gestos, tais palavras ou tais ações significam o que elas significam? $\mathrm{Ou}$ seja, como podemos caracterizar que tais elementos expressam um crime cometido em ambiente de trabalho, por exemplo. Pois, aqui não se trata de encontrar evidências diretas e objetivas do "cadáver" de um corpo humano, como no sentido convencional de um crime tal como normalmente o concebemos.

$\mathrm{Na}$ circunstância considerada acima, estamos diante de uma investigação situada em terreno um pouco mais escorregadio, isto é, em um Pano de Fundo tácito. Aí, neste Pano de Fundo tácito, emaranhado, tortuoso e obscuro da linguagem ordinária, como revelar algumas possíveis evidências da fisiologia do "crime" ou "cadáver moral" desta mente/corpo humano?

A dificuldade está em como chegar a este tipo de cadáver e desenterrá-lo como prova real de um crime objetivo à luz da lei e ética humana.

A ação que o sujeito falante desempenha com a mente, a linguagem e o corpo - tudo considerado enquanto um fato só, é razoavelmente complexa e sutil. Tal ação ali descrita tornou-se bastante conhecida pela expressão "assédio moral" ou "violência perversa no cotidiano".

Não será útil perguntar que racionalidade ou irracionalidade tautológica interna vigora nestes tipos de ação? Hirigoyan (2005) propõe alguns critérios, definições descritivas úteis e interessantes em seu livro, como as anteriormente mencionadas. 
Agora, expandimos outras perguntas por entre este exemplo; utilizando-o enquanto ponto de partida, questionamos: será possível ir além e encontrar neste emaranhado de atividades humanas que, às vezes, parecenos imbuídas de fúria e loucuras, alguns dos mesmos critérios desta racionalidade ou irracionalidade tautológica em outras situações de uso do corpo, mente e linguagem, porém com significados e propósitos bastante diferentes de uma ação perversa no cotidiano? Naturalmente, acreditamos que há. A ambigüidade, por exemplo, é muito comum na linguagem literária e mais ainda no uso da linguagem ordinária. Constatamos, neste último caso, o seu emprego no gênero discursivo das ironias diárias ou, das piadas, por exemplo.

$\mathrm{Na}$ literatura, nem sempre será o caso de apenas desfazer a ambigüidade, mas de entrar em um jogo de linguagem ativo inesgotável mediante a execução de atividades mentais que desfaçam a ambigüidade e a refaçam permanentemente.

Prosseguindo com as indagações: Quais as similaridades e dissimilaridades, conflitos e harmonias, rupturas e não-rupturas entre tantos diferentes jogos de linguagem com tantos diferentes significados e propósitos? Especificando mais o problema, qual a relação interessante que podemos estabelecer entre o caso do uso da tautologia para agressão moral camuflada, que citamos acima, estudado por Hirigoyen (2005), e estes outros dois usos, também tautológicos, que mostramos abaixo, por exemplo:

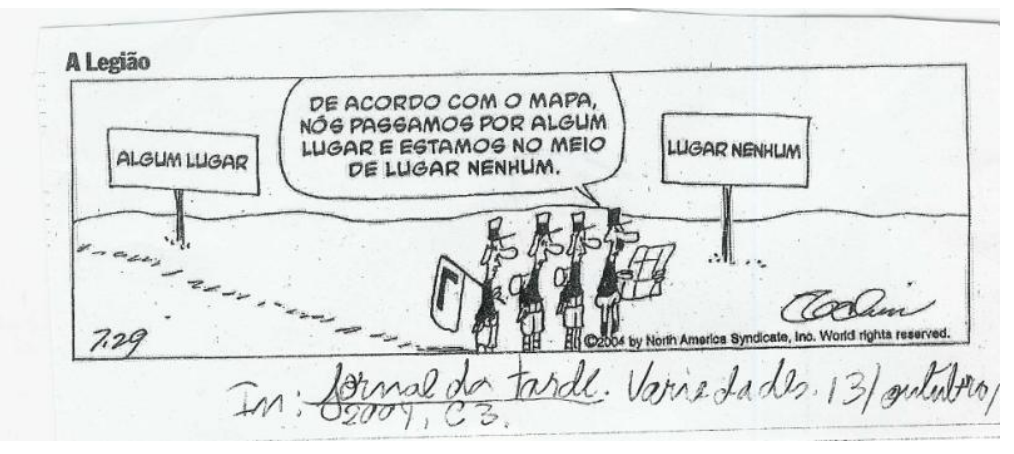

\section{Horóscopo}

Áries 21/3 a 20/4 
Há todo um mundo invisível no qual nossa humanidade está inserida e apesar de depreciado em nossa cultura moderna, ainda assim ele continua atuante. Lance mão de seus amigos que atuam em seu favor nesse mundo invisível. (In: O Estado de São Paulo. Lazer, 31/outubro/2004, p. 29.)

Que significado e propósito incomum podemos explicitar, observando a relação de graça e desgraça que se expressa entre um caso e outro, casos tão comuns da vida cotidiana como nestes três que acabamos de mostrar, a saber: a ação perversa em cotidiano de ambiente de trabalho, o mapa consultado pelos soldados da Legião em ambiente de uma tira de jornal e o mapa de vida astral, de vida presente e futura consultado por leitores de jornal e expresso em um horóscopo assinado por Oscar Quiroga, por exemplo?

Parece-nos que um dos "truques" gnômicos que se esconde por trás deles pode estar cifrado em anotações de raciocínio como nas proposições 2 , $3.144,4.461,4.462$ sobre tautologias e contradições, conforme o Wittgenstein (2004) do Tractatus.

Por quê? Porque o mundo heterogêneo que as três circunstâncias consideradas acima expressam, compõem casos que admitem todas possibilidades de verdade. Qualquer uma das possibilidades que escolhermos para cada caso, ela poderá ser verdadeira. O uso da tautologia o "truque" predominante neles - é que permite esta possibilidade. Do mesmo modo, a ambigüidade permite tal espaço de manobra. Seria algo assim feito uma bomba, um artefato de palavras engenhosamente preparado e armado, que poderia explodir em qualquer lugar, em lugar nenhum, a qualquer momento. Ao contrário, o uso da contradição, restringe qualquer situação possível. Exemplo: "O quadrado é redondo"; não há situação alguma que admita esta possibilidade: A bomba armada para explodir em lugar algum e em momento algum. Porém, duvidamos que isso não faça sentido e tentamos comprovações.

Quando, como e por quê estes três "truques" - usando a tautologia, a contradição ou a ambigüidade - ora facilmente expõem, publicam o significado e o propósito das atitudes humanas, ora facilmente eles as encobrem? 
Entendemos que investigar condições restritivas de verdade que podemos impor a cada uma destas atitudes, sobretudo em jogos de linguagem relacionados às ações éticas dos homens, não é uma fácil tarefa. Como realizar esta tarefa em alguns casos e como tais casos se entrelaçam, então? Eis aí uma das faces do problema enfrentado.

\section{Conclusão}

Como os pressupostos científicos minimalistas, políticos e filosóficos postulados por Noam Chomsky e a filosofia dos jogos de linguagem proposta por Luduwig Wittgenstein nos auxiliam ou permitem explorar esta questão? Concluímos acrescentando alguns importantes postulados de Louis Pasteur: as explicações, conselhos e compromissos de um homem de Ciência e Educação perspicazes do século passado. Louis Pasteur, perseguido por quase todos os seus colegas de profissão, pelos eminentes da época, pelo Estado e pela instituição da Academia de Ciências Médicas Francesa diz:

Pasteur - A Natureza [também a Natureza Humana] é sutil demais para se repetir.

Cientista eminente da época - O senhor declarou estar no limiar de um novo mundo./ Posso perguntar se o atravessou?

Pasteur - A Ciência dá um passo, depois outro, depois pára e reflete antes de dar o terceiro. A mãe pega o filho, coloca-o no chão e diz: 'Ande.' A criança dá um passo...outro, e pára, sem equilíbrio. A mãe teria razão de dizer: 'Está hesitando. Você jamais andará.' ?

Pasteur - Vocês jovens, médicos e cientistas do futuro, não se deixem esmorecer pela barreira do ceticismo, nem desanimar pela tristeza de certos momentos que caem sobre uma nação. Não se enraiveçam com seus oponentes, porque nenhuma teoria científica foi aceita sem oposição. Habitem a paz serena das bibliotecas e laboratórios. Digam para si mesmos, primeiro: ' - O que fiz por minha instrução?' E à medida que avançarem: '- O que estou realizando?' Até chegar o momento em que possam sentir a imensa felicidade de pensar que contribuíram, de alguma forma, para o progresso e bem-estar da Humanidade. ${ }^{1}$

\footnotetext{
${ }^{1}$ The story of Louis Pasteur (1935). Direção: William Dieterly; roteiro: Edward Chodorov, Pierre Colling e Sheridan Gibney.
} 
Pois bem, eis que já estamos no futuro, modernidade, pósmodernidade, pós-humanidade, etc. retransmitindo-nos a nós próprios e à ação pedagógica as mesmas perguntas que Pasteur fez aos homens de sua época: "O que eu fiz por minha instrução? O que estou realizando"; estas perguntas ainda nos compromete a nós todos, cientistas, estudantes e docentes, particularmente, do curso de graduação em Letras, Pedagogia, Filosofia ou Educação Física. Perguntas clássicas que Louis Pasteur atribui a jovens estudantes, futuros professores, cientistas, os não-esclarecidos e cidadãos comuns do mundo inteiro de qualquer presente ou futuro.

Estamos verificando que o espírito destas proposições do cientista francês está se arrefecendo, no mundo inteiro, sobretudo no Brasil e no interior da verdadeira Ciência que se esparrama pelo universo econômico de livre-mercado, ou seja, o funcionamento mecânico de um sentimento científico e uma educação equivocados que se sustentam pelo argumento de que conhecimento e educação são mercadoria de habilidades indutivas. Produto assim, encontra lugar e interesse apenas em "balcão de negócios", entre comerciantes vorazes de instituições escolares que transformam alunos e professores em capital de lucro financeiro. É este o proviso oculto crucial muito conveniente ao clero secular. Conseqüência: nesta indústria gramatical de transações econômicas o que resta de real conhecimento humano mesmo, pouco ou nada interessa. Mas, ainda há esperanças otimistas tais como:

No entanto, como observar as sutilezas nos atos de conhecimento tácito, nos atos de criação artística, nos atos de criação linguiísticos na linguagem comum e atos de criação científica e filosófica? Para não nos fixarmos apenas em dados puramente lingüísticos extraídos da linguagem literária, ouçamos um tipo de exemplo de percepção mental que exige do corpo humano, que ele acione a interação entre diferentes faculdades cognitivas, inclusive a faculdade lingüística, para interpretar fatores extralingüísticos; fatores extra-lingüísticos cuja expressão tácita qualquer jogo de linguagem comum requer e comporta por sua própria natureza: 
Noam Chomsky (1980), por exemplo, nos propõe o caso descrito pelo filósofo platônico inglês do século dezessete, Ralph Cudworth:

a skillful expert limner will observe many elegancies and curiosities of art and be highly pleased with several strokes and shadows in a picture, where a common eye can discern nothing at all; and a musical artist hearing a consort of exact musicians playing some excellent composure of many parts, will be exceedingly ravished with many harmonical airs and touches, that a vulgar ear will be utterly insensible of. (Chomsky, 1980, p. 228)

Chomsky, aqui, ainda chama a atenção para a expansão desta perspicácia da percepção das sutilezas, ou seja, as sutilezas que aprendemos a distinguir através da experiência vivida e convertê-la em conhecimento, de "learn to see". E admite:

But though the organ of vision is essentially fixed in structure at that time [attained at some relatively early stage in life], we may still 'learn to see' in new ways throughout our lives, for example, by applying knowledge gained later in life or through exposure to some new form of visual representation in the arts, say, cubism." (Chomsky, 1980, p.228)

Neste caso, ele atribui os resultados positivos ou negativos aos esforços de base racional, próprios do bom-senso cartesiano. Trata-se do conhecimento tácito que a mente/cérebro humana aciona para aprender e aprofundar o entendimento. Os esforços do sujeito é que podem ou não desenvolverem a percepção individual. É o momento em que o corpo humano necessita de uma sintonia fina entre diferentes capacidades mentais e físicas para fazê-las interagirem entre si durante o exercício do constante conhecimento humano.

Quanto a Wittgenstein (2001), quando se refere a Peter Schlemiehl ${ }^{2}$, o personagem da pequena novela de Adelbert von Chamisso, não nega a existência, interação e atuação destas faculdades no interior do processo. Ele apenas não se detém nelas e suspende o juízo sobre este aspecto da questão. Diz ele:

339. Thinking is not an incorporeal process which lends life and sense to speaking, which it would be possible detach from speaking, rather as the

\footnotetext{
${ }^{2}$ Chamisso, Adelbert von. A história maravilhosa de Peter Schlemihl. Posfácio de Thomas Mann (Trad. Vinicius Mazzari). São Paulo: Estação Liberdade, 1989.
} 
Devil took the shadow of Schlemiehl from the ground. - But how 'not an incorporeal process'? Am I acquainted with incorporeal processes, then, only thinking is not one of them? No; I called the expression 'an incorporeal process' to my aid in my embrassment when trying to explain the meaning of the word 'thinking' in a primitive way.

... An unsuitable type of expression is a sure means of remaining in a state of confusion. It as it were bars the way out. (Wittgenstein, 2001, p. 109)

Parafraseando. É fácil imaginar o pensamento ou a mente/cérebro "an incorporeal process" - não emprestando vida e sentido à linguagem? Não. Para nós, isto seria seria tão difícil quanto imaginar que pudéssemos retirar de uma pessoa a silhueta de sua própria sombra, como o faz o Demônio com a sombra de Peter Schlemiehl na referida novela.

Segundo Chomsky, a linguagem é algo corpóreo - a nossa inevitável sombra, mas no sentido físico da palavra "cérebro", o nosso inevitável "incorporeal process" - "mente" - que o fenômeno da luz faz acontecer conosco quando nos expomos a ela, de acordo com a "silhueta" biológica humana de cada um. No entanto, o que nós fazemos com a linguagem que nos acontece? Perguntam também o minimalismo de Chomsky, Wittgenstein e a Pragmática. A resposta é: um labirinto de atividades, entre elas, estão as atividades artísticas como as descritas por Ralph Cudworth acima, as atividades científicas, ou qualquer outra atividade da vida ordinária. Mas as atividades artísticas ou científicas, por exemplo, podem ou não acontecer, ou acontecerem de maneiras diversas; isto vai depender do modo como a pessoa usa seu corpo, a mente/cérebro e a linguagem para que lhe permita dar expressão com toda a plenitude possível típica da natureza humana.

\section{Referências}

AUSTIN, John. How to do things with words. Cambridge, Harvard University Press, 1975.

CHOMSKY, Noam. New horizons in the study of language and mind. Cambridge:Cambridge University Press, 2000.

CHOMSKY, Noam. On nature and language. Cambridge (GB): Press Syndicate of the University of Cambridge, 2005. 
CHOMSKY, Noam. The minimalist program. 3rd. printing. Cambridge Mass.: The MIT Press, 1997.

CHOMSKY, Noam. Rules and representations. New York,Columbia University Press, 1980.

FERRAZ, Eduardo \& GÓES, Marta. Império do mau. Isto é. São Paulo, v.1554, p. $14 /$ junho/1999.

HIRIGOYEN, Marie-France. Assédio moral a violência perversa no cotidiano. (Trad. Maria Helena Kühner). Rio de Janeiro: Bertrand Brasil, 2005.

WITTGENSTEIN, Ludwig. Philosophical investigations. 2nd edition (Trad. G.E.M. Anscombe) (reissued German-English edition). Oxford,Blackwell, 2001.

WITTGENSTEIN, Ludwig. Tractatus logicus-philosophicus. 6th ed., (Trad. D.F. Pears \& B. F. McGuiness). London \& New York,Routledge Classics, 2004.

WITTGENSTEIN, Ludwig. Philosophical grammar. (Trad. Anthony Kenny). Los Angeles, University of California Press, 1974. 